\title{
Digital Technologies in the Humanitarian Context
}

\section{DPH Plenary Session}

\author{
Paul Lalvani \\ Empower School of Health \\ Haryana, India \\ paul.lalvani@empowerschoolofhealth.org \\ Javier Teran Castro \\ UN Office for the Coordination of \\ Humanitarian Affairs Geneva, \\ Switzerland teran1@un.org
}

\author{
Francis D'Silva \\ Smart Care - CGI Healthcare and \\ Life Sciences Oslo, Norway \\ francis.dsilva@cgi.com \\ Raphael Brechard \\ Medicin Sans Frontiers \\ London, United Kingdom \\ Raphael.brechard@london.msf.org \\ Patty Kostkova \\ UCL IRDR Centre for Digital Public \\ Health in Emergencies \\ London, United Kingdom \\ P.kostkova@ucl.ac.uk
}

\author{
Bernadette Kumar \\ EUPHA Section on Migration and \\ Ethnic Minority Health \\ Oslo, Norway \\ Bernadette.kumar65@gmail.com \\ Caroline Wood \\ UCL IRDR Centre for Digital Public \\ Health in Emergencies \\ London, United Kingdom \\ Caroline.wood@ucl.ac.uk
}

\section{ABSTRACT}

The panel will address the potential benefits and challenges in applying digital technologies to humanitarian scenarios.

Key themes are (1) empowering the individual (or the beneficiary) and informal care-givers with knowledge tools to participate in decision-making related to one's own health (2) building capacity of healthcare professionals, at the point of care and across the continuum and levels of care (3) capturing, securing and sharing data from the field and institutions in order to better inform public health policy and the design of practices for the delivery of care and (4) aggregating data and new knowledge from the sector to accelerate the development of health technology.
Some of the barriers to experiencing the benefits from digital technologies include ability to effectively reach the target groups; public perception: show them the benefits and allay fears arising from uncertainty and hence the need for empowerment, financing: funding for efforts to transition to digitally-enabled practices, incentives: mechanisms to encourage sharing resources that ensure use and hence the longevity of digital resources and governance: structures, regulatory practices and ethical guidelines to secure responsible use of digital resources and conserving privacy and common good.

\section{KEYWORDS}

Digital Technologies, People-centered care, Humanitarian, Digital Health, Public Health, Capacity, Healthcare

Permission to make digital or hard copies of part or all of this work for personal or classroom use is granted without fee provided that copies are not made or distributed for profit or commercial advantage and that copies bear this notice and the full citation on the first page. Copyrights for third-party components of this work must be honored. For all other uses, contact the Owner/Author.

DPH' 19, November 20-23, 2019, Marseille, France

(C) 2019 Copyright is held by the owner/author(s)

ACM ISBN 978-1-4503-7208-4/19/11.

DOI: https://doi.org/10.1145/3357729.3365105 